\title{
Altered Resting-State Functional Connectivity in Cortical Networks in Psychopathy
}

\author{
[Carissa L. Philippi, ${ }^{1}$ Maia S. Pujara, ${ }^{1}$ Julian C. Motzkin, ${ }^{1}$ Joseph Newman, ${ }^{2}$ Kent A. Kiehl, $, 3,4,5$ and \\ ․ㅣㄹ. Michael Koenigs ${ }^{1}$ \\ Departments of ${ }^{1}$ Psychiatry and ${ }^{2}$ Psychology, University of Wisconsin-Madison, Madison, Wisconsin 53706, ${ }^{3}$ Mind Research Network, An Affiliate of \\ Lovelace Biomedical and Environmental Research Institute, Albuquerque, New Mexico 87131, and Departments of ${ }^{4}$ Psychology, ${ }^{5} \mathrm{Neuroscience}$, and ${ }^{6} \mathrm{Law}$, \\ University of New Mexico, Albuquerque, New Mexico 87131
}

Psychopathy is a personality disorder characterized by callous antisocial behavior and criminal recidivism. Here we examine whether psychopathy is associated with alterations in functional connectivity in three large-scale cortical networks. Using fMRI in 142 adult male prison inmates, we computed resting-state functional connectivity using seeds from the default mode network, frontoparietal network, and cingulo-opercular network. To determine the specificity of our findings to these cortical networks, we also calculated functional connectivity using seeds from two comparison primary sensory networks: visual and auditory networks. Regression analyses related network connectivity to overall psychopathy scores and to subscores for the "factors" and "facets" of psychopathy: Factor 1, interpersonal/affective traits; Factor 2, lifestyle/antisocial traits; Facet 1, interpersonal; Facet 2, affective; Facet 3, lifestyle; Facet 4, antisocial. Overall psychopathy severity was associated with reduced functional connectivity between lateral parietal cortex and dorsal anterior cingulate cortex. The two factor scores exhibited contrasting relationships with functional connectivity: Factor 1 scores were associated with reduced functional connectivity in the three cortical networks, whereas Factor 2 scores were associated with heightened connectivity in the same networks. This dissociation was evident particularly in the functional connectivity between anterior insula and dorsal anterior cingulate cortex. The facet scores also demonstrated distinct patterns of connectivity. We found no associations between psychopathy scores and functional connectivity within visual or auditory networks. These findings provide novel evidence on the neural correlates of psychopathy and suggest that connectivity between cortical association hubs, such as the dorsal anterior cingulate cortex, may be a neurobiological marker of the disorder.

Key words: antisocial personality disorder; fMRI; fronto-parietal network; functional connectivity; psychopathy; resting-state

\section{Introduction}

Psychopathy is a personality disorder characterized by a callous lack of empathy and impulsive antisocial behavior. Present in approximately one-quarter of adult prison inmates, psychopathy is a significant predictor of violent crime and recidivism (Harris et al., 1991; Hare, 2003). Thus, identifying the psychological and neurobiological mechanisms underlying this disorder could have profound implications for the clinical and legal management of psychopathic criminals, as well as for the basic understanding

Received Dec. 9, 2014; revised Feb. 10, 2015; accepted March 9, 2015.

Author contributions: C.L.P., J.N., K.A.K., and M.K. designed research; C.L.P., M.S.P., and J.C.M. performed research; C.L.P., M.S.P., and J.C.M. analyzed data; C.L.P., M.S.P., J.C.M., J.N., K.A.K., and M.K. wrote the paper.

This work was supported by National Institutes of Health Grants MH070539 (principle investigator, KAK), DA026505 (principle investigator, K.A.K.), MH078980 (principle investigator, J.N.), MH087525 (principle investigator, J. Decety), MH090169 (principle investigator, D.S. Kosson). We thank the many individuals at the Wisconsin Department of Corrections for making this research possible and are especially indebted to Deputy Warden Tom Nickel and Dr. Kevin Kallas. We also thank the Mind Research Network staff Keith Harenski, Dr. Nate Anderson, and Mike Maurer for their assistance with MRI data collection.

The authors declare no competing financial interests.

Correspondence should be addressed to Carissa L. Philippi and Michael Koenigs, Department of Psychiatry, University of Wisconsin-Madison, 6001 Research Park Boulevard, Madison, WI 53719. E-mail: cphilippi@wisc.edu; mrkoenigs@wisc.edu.

DOI:10.1523/JNEUROSCI.5010-14.2015

Copyright $\odot 2015$ the authors $\quad 0270-6474 / 15 / 356068-11 \$ 15.00 / 0$ of human social behavior. Initial research on the neural correlates of psychopathy has demonstrated abnormalities in the structure and function of numerous cortical and subcortical brain regions, with the predominance of findings highlighting frontal, temporal, and limbic areas involved in social and affective processing (Yang and Raine, 2009; Blair, 2010; Koenigs et al., 2011; Anderson and Kiehl, 2012). However, the neural correlates of the disorder have yet to be identified comprehensively.

One major knowledge gap in this area of research concerns the role that alterations in cortical network connectivity may play in psychopathy. In recent years, psychiatric illnesses have come to be understood as disorders of neural circuits (Morris and Cuthbert, 2012). This perspective, which underscores large-scale network connectivity as a critical biological parameter related to mental health, is supported by a rapidly expanding body of neuroimaging research that associates a variety of psychiatric disorders with altered restingstate connectivity in distinct cortical networks (Menon, 2011; Sylvester et al., 2012; Whitfield-Gabrieli and Ford, 2012). In particular, Menon (2011) suggests that dysfunction in connectivity within and between three major cortical networks - the default mode network, central executive/frontoparietal network, and salience/cinguloopercular network-may underlie various psychiatric and neurological disorders. However, to date, no study has examined 
Table 1. Participant characteristics

\begin{tabular}{|c|c|c|c|c|c|c|c|c|c|c|c|c|c|}
\hline \multirow[b]{2}{*}{ Variable } & \multicolumn{4}{|c|}{ All participants $(n=142)$} & \multicolumn{4}{|c|}{ Nonpsychopathic $(n=49)$} & \multicolumn{4}{|c|}{ Psychopathic $(n=46)$} & \multirow[b]{2}{*}{$p^{a}$} \\
\hline & Mean & SD & $\%$ & $n$ & Mean & SD & $\%$ & $n$ & Mean & SD & $\%$ & $n$ & \\
\hline Age & 30.2 & 6.8 & & & 30.4 & 6.7 & & & 29.6 & 6.9 & & & 0.58 \\
\hline $10^{b}$ & 98.0 & 11.1 & & & 98.6 & 11.7 & & & 99.1 & 10.0 & & & 0.84 \\
\hline Total PCL-R score & 23.9 & 7.7 & & & 14.8 & 3.6 & & & 32.1 & 1.6 & & & $<0.001$ \\
\hline Factor 1 score & 8.8 & 3.5 & & & 5.1 & 2.2 & & & 12.1 & 1.8 & & & $<0.001$ \\
\hline Factor 2 score & 13.2 & 4.3 & & & 8.2 & 2.8 & & & 17.2 & 1.3 & & & $<0.001$ \\
\hline Facet 1 score & 3.2 & 2.0 & & & 1.3 & 1.1 & & & 4.9 & 1.6 & & & $<0.001$ \\
\hline Facet 4 score & 6.2 & 2.8 & & & 3.2 & 2.0 & & & 8.7 & 1.0 & & & $<0.001$ \\
\hline SUD $^{c}$ & & & 67.2 & 90 of 134 & & & 40.9 & 18 of 44 & & & 76.7 & 33 of 43 & 0.001 \\
\hline \multicolumn{14}{|l|}{ Race } \\
\hline Caucasian & & & 56.3 & 80 of 142 & & & 73.5 & 36 of 49 & & & 58.7 & 27 of 46 & 0.14 \\
\hline African American & & & 41.5 & 59 of 142 & & & 26.5 & 13 of 49 & & & 41.3 & 19 of 46 & 0.14 \\
\hline Native American & & & 0.7 & 1 of 142 & & & 0.0 & 0 of 49 & & & 0.0 & 0 of 46 & N/A \\
\hline
\end{tabular}

Participant demographic and neuropsychological information is presented for all participants and psychopathic and nonpsychopathic groups.

${ }^{a} p$ values are reported for two-sample $t$ tests (for age, $1 Q$, and psychopathy scores) and Fisher's exact tests (for SUD and Race) comparing psychopathic and nonpsychopathic inmates.

${ }^{b} \mathrm{IQ}$ was estimated by either the Shipley Institute of Living Scale (Zachary, 1986) or the Wechsler Adult Intelligence Scale version 3.

'SUD statistics are based on diagnosis of abuse or dependence in the Structured Clinical Interview for Diagnostic and Statistical Manual of Mental Disorders, Edition 4 Disorders (First, 2002 ), which was administered to 134 of 142 participants in the study.

systematically whether psychopathy is associated with alterations of resting-state functional connectivity within and between these three major cortical association networks. Given that psychopathy involves severe deficits in the integration of social and affective information into decision-making (Cleckley, 1976; Newman and Lorenz, 2003) - a function that would presumably depend critically on patent connectivity among these same cortical networks-there is strong reason to hypothesize alterations in the resting-state connectivity in these networks. This study is the first to test this hypothesis in a large sample of criminal offenders with a wide range of psychopathy severity.

Furthermore, the large and diverse inmate sample affords us a unique opportunity to examine the neural correlates of the two primary "factors" and the four "facets," or dimensions, of psychopathy. Factor 1 corresponds to the interpersonal/affective traits of psychopathy (e.g., callousness, egocentrism), whereas Factor 2 corresponds to the lifestyle/antisocial features (e.g., impulsivity, irresponsibility; Hare et al., 1990). Factor 1 can be further subdivided into Facet 1 (interpersonal traits) and Facet 2 (affective traits), whereas Factor 2 can be further subdivided into Facet 3 (lifestyle traits) and Facet 4 (antisocial traits; Hare and Neumann, 2005). Although several previous neuroimaging studies have identified neural correlates of individual psychopathy factors and/or facets (Yang et al., 2005, 2009; de Oliveira-Souza et al., 2008; Ermer et al., 2012; Contreras-Rodríguez et al., 2014), none of these studies have examined resting-state functional connectivity across such a broad range of psychopathy severity. In summary, this study uses resting-state fMRI in a large sample of adult prison inmates to identify novel neural correlates of psychopathy.

\section{Materials and Methods}

Participants. One hundred fifty-five adult male inmates, recruited from a medium-security Wisconsin correctional facility, participated in the present study. Thirteen subjects were excluded because of excessive head motion during the scan (see below, Preprocessing of functional data). Participants were selected based on the following inclusion criteria: (1) age $<45$ years; (2) intelligence quotient (IQ) $>70$; (3) no history of psychosis or bipolar disorder; (4) no history of significant head injury or postconcussion symptoms; and (5) no current use of psychotropic medications. Informed consent was obtained both orally and in writing.
Psychopathy was assessed for all participants using the Psychopathy Checklist Revised (PCL-R; Hare, 2003). The PCL-R is a 20-item scale. Scores for each item were rated as 0,1 , or 2 based on the severity of each trait determined from a semi-structured interview and file review administered by trained research assistants. Inter-rater reliability (intraclass correlation) for total PCL-R score was 0.98 based on 10 dual ratings. Total PCL-R, Factor 1 (interpersonal/affective traits), Factor 2 (lifestyle/ antisocial traits), Facet 1 (interpersonal traits), Facet 2 (affective traits), Facet 3 (lifestyle traits), and Facet 4 (antisocial traits) scores were used for separate regression analyses. For the group analyses, participants were classified as psychopathic if their PCL-R scores were $\geq 30(n=46)$ and nonpsychopathic if their PCL-R scores were $\leq 20$ ( $n=49$; Hare, 2003). For demographic and neuropsychological information, see Table 1.

MRI data acquisition. All MRI data were acquired on correctional facility grounds with the Siemens 1.5T Avanto Mobile MRI System of the Mind Research Network with advanced SQ gradients (maximum slew rate, $200 \mathrm{~T} \cdot \mathrm{m}^{-1} \cdot \mathrm{s}^{-1} ; 346 \mathrm{~T} \cdot \mathrm{m}^{-1} \cdot \mathrm{s}^{-1}$ vector summation; rise time, $200 \mu \mathrm{s})$ equipped with a 12 -element head coil. Head motion was limited using padding and restraint.

Resting-state functional images were collected while subjects lay still and awake, passively viewing a fixation cross for $5.5 \mathrm{~min}$ (158 volumes). T2*-weighted gradient-echo functional echo planar images (EPIs) were acquired with the following parameters: repetition time (TR), $2000 \mathrm{~ms}$; echo time (TE), $39 \mathrm{~ms}$; flip angle, $75^{\circ}$; field of view (FOV), $24 \times 24 \mathrm{~cm}$; matrix, $64 \times 64$; slice thickness, $4 \mathrm{~mm}$; gap, $1 \mathrm{~mm}$; voxel size, $3.75 \times$ $3.75 \times 5 \mathrm{~mm} ; 27$ sequential axial oblique slices. A T1-weighted structural image was acquired using a four-echo MPRAGE sequence (TR, 2530; TE, 1.64, 3.5, 5.36, $7.22 \mathrm{~ms}$; flip angle, $7^{\circ}$; FOV, $256 \times 256 \mathrm{~mm}$; matrix, $128 \times$ 128; slice thickness, $1.33 \mathrm{~mm}$; voxel size, $1 \times 1 \times 1.33 \mathrm{~mm}$; 128 interleaved sagittal slices). All four echoes were averaged into a single highresolution image that was used to aid in the spatial normalization of EPI volumes and visualization of group statistics.

Preprocessing of functional data. All fMRI data analysis was performed using AFNI (Automated Functional Neuro-Imaging; Cox, 1996) and FSL (FMRIB Software Library; http://fsl.fmrib.ox.ac.uk/fsl/fslwiki/). The following preprocessing steps were performed: (1) EPI volumes were slice time corrected using the first slice as a reference and (2) motion corrected by rigid body alignment to the first EPI acquisition, (3) images were deobliqued, (4) the first three volumes were omitted, (5) data were then motion corrected (3dvolreg function in AFNI) and (6) despiked to remove extreme time series outliers and then (7) bandpass filtered $(0.009<f<0.08)$ and spatially smoothed with a $6 \mathrm{~mm}$ full-width at 
half-maximum Gaussian kernel (Fox et al., 2005). The skull-stripped anatomical scan for each participant was rigidly coregistered with the EPI and diffeomorphically aligned to Montreal Neurological Institute (MNI)-152 template space using a symmetric normalization algorithm (Avants and Gee, 2004). The transformation matrix from this registration procedure was then used to align the EPI scans for each participant to MNI-152 space. Finally, the EPI scans were resampled to $3 \mathrm{~mm}$ cubic voxels for subsequent functional connectivity analyses.

Because individual differences in subject motion can contribute to resting-state correlations (Power et al., 2012; Satterthwaite et al., 2013; Yan et al., 2013), we examined motion for each subject. We excluded subjects with mean framewise motion displacement (i.e., volume to volume movement across the time series) $>2 \mathrm{~mm}$ and/or total scan time $<4$ min after censoring all time points with framewise motion displacement $>0.2 \mathrm{~mm}$ and extreme time series displacement (i.e., time points in which $>10 \%$ of voxels were outliers; Power et al., 2012; Satterthwaite et al., 2013; Yan et al., 2013). These specific thresholds for motion (mean framewise motion displacement $<2 \mathrm{~mm}$ and $>4$ min remaining after censoring time points for both framewise motion $>0.2 \mathrm{~mm}$ and extreme time series displacement $>10 \%$ of voxels) were selected based on previous research to provide the most contemporary and conservative criteria for motion correction. Thus, 13 subjects were excluded from additional analysis $(n=3$ with mean framewise motion $>2 \mathrm{~mm}, n=13$ with total scan time $<4$ min after motion censoring). In the remaining sample (after censoring), there were no significant differences between groups in root mean squared head-position change [psychopathic, $0.138 \pm 0.08$ (mean $\pm \mathrm{SD}$ ); nonpsychopathic, $0.122 \pm 0.06 ; p=0.25$; Power et al., 2012] or in the number of frames remaining (psychopathic, $147.83 \pm 8.97$; nonpsychopathic, $148.43 \pm 8.28, p=0.73)$.

Normalized T1 anatomical images were segmented into gray matter, white matter, and CSF segments using FAST (FMRIB Automated Segmentation Tool) in FSL (Zhang et al., 2001). White matter and CSF segments were used as masks to extract a representative time series from each tissue type.

Region of interest selection for cortical networks. To assess functional connectivity for three main cortical networks of interest [default mode $(\mathrm{DMN})$, frontoparietal (FPN), and cingulo-opercular $(\mathrm{CON})]$, we selected a priori seed regions of interest (ROIs) that have been identified from previous studies (Andrews-Hanna et al., 2007; Dosenbach et al., 2007; Table 2). To determine the specificity of our findings to these cortical networks, we also selected two frequently used primary sensory comparison networks [visual (VN) and auditory (AN); Andrews-Hanna et al., 2007; Boveroux et al., 2010]. Given the aim of the study on connectivity within and between DMN, FPN, and CON, we focus our results on clusters that fall within these networks. We defined the regions within these networks based on a recent large-scale resting-state study $(n=1000$ subjects) that demonstrated the reliability and reproducibility of these same cortical networks (Yeo et al., 2011). Specifically, we used masks for the DMN (network 7), FPN (network 6), dorsal attention network (network 3), and CON (network 4) (http://www.freesurfer.net/fswiki/ CorticalParcellation; Yeo et al., 2011). Each network mask was aligned to MNI-152 space and resampled to $3 \mathrm{~mm}^{3}$ resolution. Based on these network parcellations, the following regions were included in each of our cortical networks of interest if they overlapped with the network masks mentioned above: (1) DMN: the medial prefrontal cortex (mPFC), the superior frontal gyrus extending into superior portions of the middle frontal gyrus, the posterior cingulate cortex (PCC)/retrosplenial cortex, the inferior and medial lateral temporal gyri, and the inferior parietal lobule (angular gyrus); (2) FPN: the superior parietal lobule [including the intraparietal sulcus (IPS)], the superior, middle, and inferior frontal gyri [including the dorsolateral PFC (dlPFC)], the precuneus, and the inferior temporal cortex; (3) dorsal attention network: the precuneus (the superior portion bilaterally); and (4) CON: the dorsal anterior cingulate cortex (dACC)/mesial frontal cortex (msFC), the anterior insula/ frontal operculum (aIfO), the mid-insula, and the supramarginal gyrus. The regions included in the comparison networks were the following: (1) $\mathrm{VN}$ : the lingual gyrus and the cuneus; and (2) AN: the primary auditory cortex/superior temporal gyrus.
Table 2. Cortical networks evaluated for resting-state functional connectivity

\begin{tabular}{lc}
\hline Seeds & Coordinates \\
\hline Main cortical networks of interest & \\
DMNN $^{a}$ & \\
mPFC & $1,40,19$ \\
PCC/retrosplenial cortex & $-1,-53,25$ \\
L IPL & $-45,-70,24$ \\
R IPL & $53,-68,25$ \\
FPN $^{b}$ & \\
L IPS & $-31,-63,42$ \\
R IPS & $30,-65,39$ \\
L dIPFC & $-43,21,38$ \\
R dIPFC & $43,21,38$ \\
CON & \\
L alf0 & $-35,14,6$ \\
R alfO & $36,16,5$ \\
dACC/msFC & $-1,8,50$ \\
Comparison networks & \\
VN $^{a}$ & \\
Left visual cortex & \\
Right visual cortex & $-19,-98,3$ \\
ANc & $19,-98,3$ \\
Left Heschl's gyrus & \\
Right Heschl's gyrus & $-40,-23,7$ \\
\hline
\end{tabular}

All seed ROIs are reported in MNI-152 template space.

${ }^{a}$ Default mode and visual network seeds were selected from Andrews-Hanna et al., 2007.

${ }^{b}$ Frontoparietal and cingulo-opercular seeds were selected from Dosenbach et al., 2007.

'Auditory network seeds were selected from Boveroux et al., 2010.

Functional connectivity analysis. To evaluate functional connectivity for each of the seed ROIs, we generated a spherical $6 \mathrm{~mm}$ radius seed centered on the coordinates for each ROI using the Wake Forest University PickAtlas (Maldjian et al., 2003). All seeds were aligned to MNI-152 space.

Functional connectivity was assessed for each network seed ROI using the mean resting-state BOLD time series, extracted for each participant. The mean time series from each ROI was included in a GLM with 15 regressors of no interest: 1-12, six motion parameters (three translations and three rotations) obtained from the rigid-body alignment of EPI volumes and their six derivatives; 13 , the white matter time series; 14 , the ventricular (CSF) time series; and 15, a second-order polynomial to model baseline signal and slow drift. To further control for subject motion during the GLM, volumes were censored for extreme time series displacement (i.e., time points in which $>10 \%$ of voxels were outliers) and framewise motion displacement (i.e., volume to volume movement) $>0.2 \mathrm{~mm}$ (Power et al., 2012; Yan et al., 2013).

To convert the output of $R^{2}$ values from the GLM to correlation coefficients $(r)$, the following equation implemented in AFNI was used: 3dcalc -a Corr_subject1.nii '[sub-brick for $R^{2}$ ]' -b Corr_subject1.nii "[sub-brick for Beta]" -expr 'ispositive $(b) \times \operatorname{sqrt}(a)-$ isnegative $(b) \times$ sqrt(a)'. Then, correlation coefficients for each network seed ROI were converted to $\mathrm{z}$ scores via Fisher's $r$ to $z$ transform and corrected for degrees of freedom using the following equation: $z=\log ((1+r) /(1-$ $r)) \times \sqrt{ }((n-3)) / 2$, where $n$ is degrees of freedom (i.e., time points in the fMRI resting-state scan after censoring). The resulting $\mathrm{z}$-score maps were entered into second-level statistical analyses.

Regression analyses for seed-based functional connectivity. We performed linear regression analyses (3dRegAna function in AFNI) to examine the relationship between PCL-R scores and functional connectivity for all cortical network seed ROIs. We performed separate regressions for each of the following PCL-R scores: total PCL-R, Factor 1 (covarying for Factor 2), Factor 2 (covarying for Factor 1), Facet 1, Facet 2, Facet 3, and Facet 4. To correct for multiple comparisons, we used familywise error (FWE) correction at the cluster level using a wholebrain mask (3dClustSim function in AFNI; Forman et al., 1995; Carp, 2012) and applied cluster extent thresholding to our regression results. The cluster extent threshold corresponded to the statistical probability ( $\alpha=0.05$, or $5 \%$ chance) of identifying a random noise cluster at a 
A
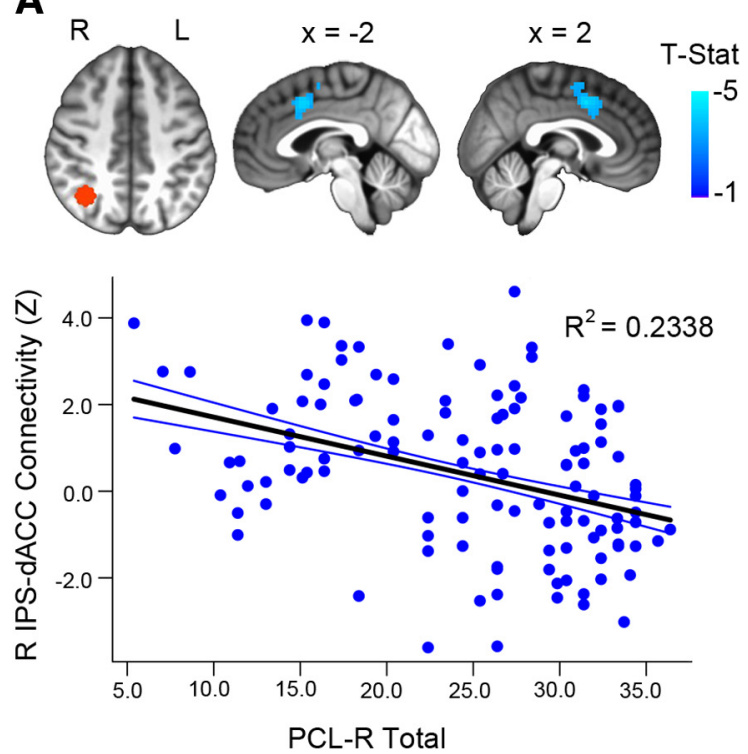

B
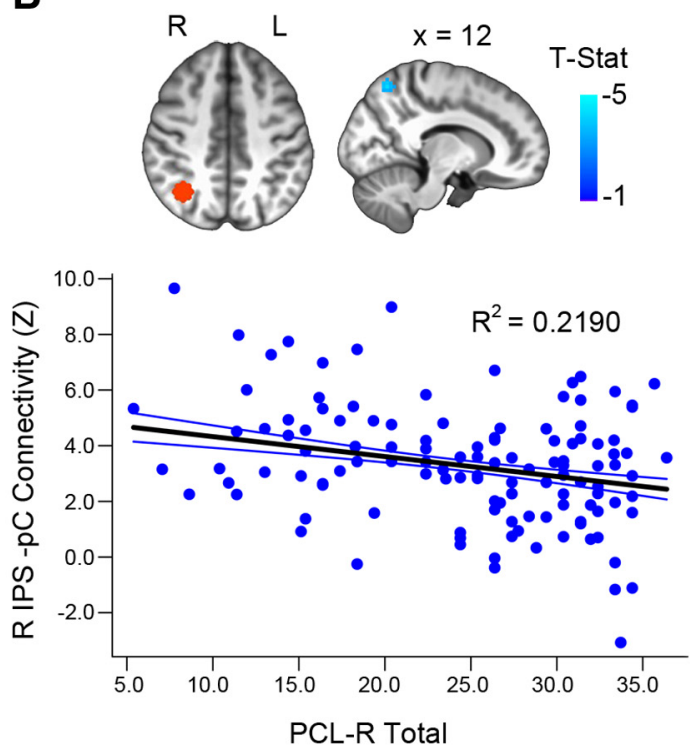

Figure 1. Total PCL-R scores were related inversely to functional connectivity between the R IPS and the bilateral dACC and the right precuneus. Top row, Seed ROIs (red- orange) for the R IPS displayed significant regression results $\left(p_{\mathrm{FWE}}<0.05\right)$ for total PCL-R scores and RIPS connectivity. All results and seed ROIs are displayed on the group average structural MRI in MNI space. Bottom row, Scatter plots show the relationship between total PCL-R scores and the connectivity values for the RIPS and the bilateral $\mathrm{dACC}(\boldsymbol{A})$ and the RIPS and the right precuneus (pC; $\boldsymbol{B}$ ). Each regression line (plotted in black) depicts the predicted model for total PCL-R and R IPS connectivity including covariates (age, SUD, race, and IQ); confidence intervals are plotted in blue lines.

predefined voxelwise (i.e., whole-brain) threshold of $p<0.005$ (uncorrected). Using this whole-brain FWE cluster correction, a clustercorrected size of $\geq 72$ voxels was significant at $p_{\mathrm{FWE}}<0.05$ in the regression analyses reported below for PCL-R scores. Regression results were overlaid on the normalized mean anatomical image.

Follow-up regression analyses were performed for all significant results to account statistically for potential differences in age, substance use disorder (SUD), race, and IQ. We first extracted the average $\mathrm{z}$ score from all significant clusters identified for each subject, and then we ran separate regressions (in $\mathrm{R}$ ) to examine the association between the average $\mathrm{z}$ score for each significant cluster and the PCL-R score after controlling for age, SUD, race, and IQ. Regressions with PCL-R factor scores also included partial correlations (e.g., models with Factor 1 also contained Factor 2, along with age, SUD, race, and IQ). Regressions with PCL-R facet scores included the facet score after controlling for age, SUD, race, and IQ. Importantly, all results were corrected for multiple tests using the Holm-Bonferroni correction method (Holm, 1979). Using the HolmBonferroni method, we performed the following steps: (1) ordered the $p$ values for all regression results from smallest to largest, (2) multiplied the smallest $p$ value by $[k-(n-1)]$, where $k$ is the number of null hypothesis tests or contrasts and $n$ is the test number (i.e., $n=1$ for the first $p$ value in the ordered list), (3) multiplied the next smallest $p$ value by $[k-$ $(n-1)]$ (i.e., $n=2$ for the second $p$ value), and (4) continued this iterative process for all remaining $p$ values until the Holm-Bonferroni corrected $p$ value exceeded 0.05 . Below we only report results that remained significant after the inclusion of relevant covariates (age, SUD, race, IQ, and Factor 1/Factor 2) and Holm-Bonferroni correction, at $p<0.05$.

Group comparisons for seed-based functional connectivity. As a follow-up to the seed-based regression analyses, we investigated differences in functional connectivity between psychopathic and nonpsychopathic inmates. We performed unpaired two-sample $t$ tests on the z-score maps derived from each seed ROI from the seed-based functional connectivity analysis. As described above for the regressions, we used an FWE correction approach at the cluster level using a whole-brain mask to correct for multiple comparisons at the voxelwise level (Forman et al., 1995; Carp, 2012). In this group comparison, a cluster size of $\geq 89$ voxels was significant at $p_{\mathrm{FWE}}<0.05$ in the two-sample $t$ tests reported. Group correlation maps were overlaid on the normalized mean anatomical image.

\section{Results}

Regression analysis: total PCL-R

For the FPN (Fig. 1, Table 3), higher total PCL-R scores were associated with significantly diminished connectivity between the right (R) IPS and the bilateral dACC of the CON and right precuneus of the FPN. There were no significant relationships between total PCL-R scores and functional connectivity for any seeds of the DMN, CON, or either of the comparison networks.

\section{Between-group analysis: psychopathic versus} nonpsychopathic inmates

Similar to the regression analyses with total PCL-R, in the between-group analysis, we found significant differences for only FPN seeds. Psychopathic inmates exhibited significantly reduced functional connectivity between the R IPS and right precuneus (within the FPN) and between the R IPS and left (L) dACC (extending bilaterally) and the right insula of the CON (Fig. 2, Table $3)$. There were no significant group differences for either of the two comparison networks.

\section{Regression analysis: PCL-R factor scores}

For the DMN (Fig. 3, Table 3), the individual factor scores were associated with distinct patterns of functional connectivity. Higher Factor 1 scores were associated with significantly decreased connectivity between the medial and lateral regions of the DMN [PCC seed: right superior frontal gyrus; L inferior parietal lobule (IPL) seed: left superior frontal gyrus; R IPL seed: left posterior cingulate]. In contrast, higher Factor 2 scores were associated with significantly increased functional connectivity between the medial prefrontal and parietal regions of the DMN (mPFC seed: left dorsomedial PFC, left superior frontal gyrus, right posterior cingulate; PCC seed: left dorsomedial PFC, left superior frontal gyrus extending to middle frontal gyrus). In addition, higher Factor 2 scores were associated with significant functional connectivity between the mPFC seed and left precuneus (within the FPN). 


\begin{tabular}{|c|c|c|c|}
\hline Seed & Brain region & MNI coordinates & Cluster size (voxels), $t$ value \\
\hline \multicolumn{4}{|c|}{ Regression results: main cortical networks of interest } \\
\hline \multicolumn{4}{|c|}{ DMN } \\
\hline \multicolumn{4}{|l|}{ Factor 1} \\
\hline $\mathrm{PCC}$ & Right superior frontal gyrus & $32,18,51$ & $107,-4.07$ \\
\hline LIPL & Left superior frontal gyrus & $-25,12,54$ & $127,-4.50$ \\
\hline RIPL & Left posterior cingulate & $-7,-36,30$ & $149,-4.24$ \\
\hline \multicolumn{4}{|l|}{ Factor 2} \\
\hline $\mathrm{mPFC}$ & Left dorsomedial prefrontal & $-4,30,24$ & $268,4.54$ \\
\hline $\mathrm{mPFC}$ & Left superior frontal gyrus & $-16,12,63$ & $167,4.26$ \\
\hline $\mathrm{mPFC}$ & Right posterior cingulate & $5,-27,30$ & $115,4.42$ \\
\hline $\mathrm{mPFC}$ & Left precuneus & $-1,-75,33$ & $80,3.75$ \\
\hline $\mathrm{PCC}$ & Left dorsomedial PFC & $-7,36,51$ & $124,4.18$ \\
\hline $\mathrm{PCC}$ & Left superior frontal gyrus extending to middle frontal gyrus & $-28,12,60$ & $84,4.23$ \\
\hline \multicolumn{4}{|c|}{ - } \\
\hline \multicolumn{4}{|l|}{ Total PCL-R } \\
\hline RIPS & Bilateral dorsal anterior cingulate & $2,6,42$ & $103,-4.22$ \\
\hline RIPS & Right precuneus & $17,-78,48$ & $74,-4.17$ \\
\hline \multicolumn{4}{|l|}{ Factor 1} \\
\hline LIPS & Right superior frontal gyrus & $26,54,27$ & $81,-4.41$ \\
\hline RIPS & Left precuneus & $-13,-78,51$ & $157,-4.91$ \\
\hline L dIPFC & Left superior parietal lobule & $-37,-54,48$ & $76,-3.94$ \\
\hline \multicolumn{4}{|l|}{ Factor 2} \\
\hline L dIPFC & Right middle frontal gyrus & $44,36,24$ & $73,4.66$ \\
\hline L dIPFC & Right supramarginal gyrus & $53,-39,45$ & $73,3.79$ \\
\hline \multicolumn{4}{|l|}{$\mathrm{CON}$} \\
\hline \multicolumn{4}{|l|}{ Factor 1} \\
\hline Lalf0 & Right dACC/msFC & $5,0,66$ & $261,-4.95$ \\
\hline Lalf0 & Right anterior insula & $38,21,-6$ & $103,-3.64$ \\
\hline Lalf0 & Left supramarginal gyrus & $-52,-33,21$ & $82,-4.36$ \\
\hline Ralf0 & Right dorsal anterior cingulate (cluster extends bilaterally) & $5,-3,69$ & $384,-5.37$ \\
\hline Ralf0 & Right postcentral gyrus extending to supramarginal gyrus & $59,-24,27$ & $196,-4.82$ \\
\hline Ralf0 & Right inferior frontal gyrus extending to insula & $56,6,15$ & $160,-4.30$ \\
\hline Ralf0 & Left inferior frontal gyrus extending to insula & $-55,9,3$ & $104,-4.84$ \\
\hline \multicolumn{4}{|c|}{ 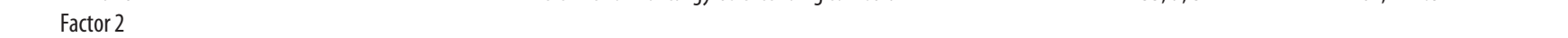 } \\
\hline Lalf0 & Right mid-insula extending to anterior insula & $35,3,-9$ & $138,4.84$ \\
\hline Ralf0 & Left dorsal anterior cingulate (cluster extends bilaterally) & $-7,0,33$ & $235,4.44$ \\
\hline Ralf0 & Right postcentral gyrus extending to supramarginal gyrus & $65,-18,21$ & $166,4.92$ \\
\hline Ralf0 & Right inferior frontal gyrus extending to insula & $47,12,6$ & $163,4.25$ \\
\hline Ralf0 & Right medial frontal gyrus & $5,-3,66$ & $156,4.99$ \\
\hline R alf0 & Left inferior frontal gyrus & $-55,9,0$ & $95,5.40$ \\
\hline $\mathrm{dACC} / \mathrm{msFC}$ & Right precuneus extending to posterior cingulate & $17,-66,39$ & $79,4.37$ \\
\hline \multicolumn{4}{|c|}{ Group results: main cortical networks } \\
\hline \multicolumn{4}{|c|}{ FPN } \\
\hline \multicolumn{4}{|c|}{ Psychopathic $<$ nonpsychopathic } \\
\hline RIPS & Left dorsal anterior cingulate (cluster extends bilaterally) & $-1,12,39$ & $151,-4.37$ \\
\hline RIPS & Right precuneus & $8,-57,57$ & $126,-4.48$ \\
\hline RIPS & Right insula & $38,3,-3$ & $81,-4.81$ \\
\hline
\end{tabular}

Significant within-network clusters for psychopathy scores (total PCL-R, Factor 1, and Factor 2) from the regression and between-group comparison analyses. All regression results reported were significant after controlling for age, SUD, race, and IQ (cluster-corrected $p_{\mathrm{FWE}}=0.05$; Holm-Bonferroni corrected, each $p<0.05$ ).

For the FPN (Fig. 3, Table 3), higher Factor 1 scores, similar to total PCL-R, were associated with significantly decreased connectivity between the lateral parietal, medial parietal, and lateral prefrontal regions of the FPN (L IPS seed: right superior frontal gyrus; R IPS seed: left precuneus; L dlPFC seed: left superior parietal lobule). In contrast, higher Factor 2 scores were associated with significantly increased functional connectivity between lateral prefrontal regions of the FPN (L dlPFC seed: right middle frontal gyrus) and right supramarginal gyrus of the CON (L dlPFC seed).

For the CON (Fig. 3, Table 3), as in the other two networks, the individual factor scores were again associated with distinct patterns of functional connectivity. Higher Factor 1 scores were associated with decreased connectivity between the insula, ante- rior cingulate, and lateral parietal regions of the CON (L aIfO seed: right dorsal anterior cingulate extending bilaterally, right anterior insula, left supramarginal gyrus; R aIfO seed: right dorsal anterior cingulate, right inferior frontal gyrus/insula, left inferior frontal gyrus/insula, right postcentral gyrus extending to supramarginal gyrus), whereas higher Factor 2 scores were associated with increased connectivity between the insula, anterior cingulate, and lateral parietal regions of the $\mathrm{CON}$ (L aIfO seed: right mid-insula; R aIfO seed: left dorsal anterior cingulate extending bilaterally, right supramarginal gyrus, right inferior frontal gyrus/ insula, right medial frontal gyrus, left inferior frontal gyrus). Higher Factor 2 scores were also associated with increased connectivity between the $\mathrm{dACC} / \mathrm{msFC}$ seed and right precuneus of the FPN. 


\section{Group Differences in Functional Connectivity with R IPS seed}

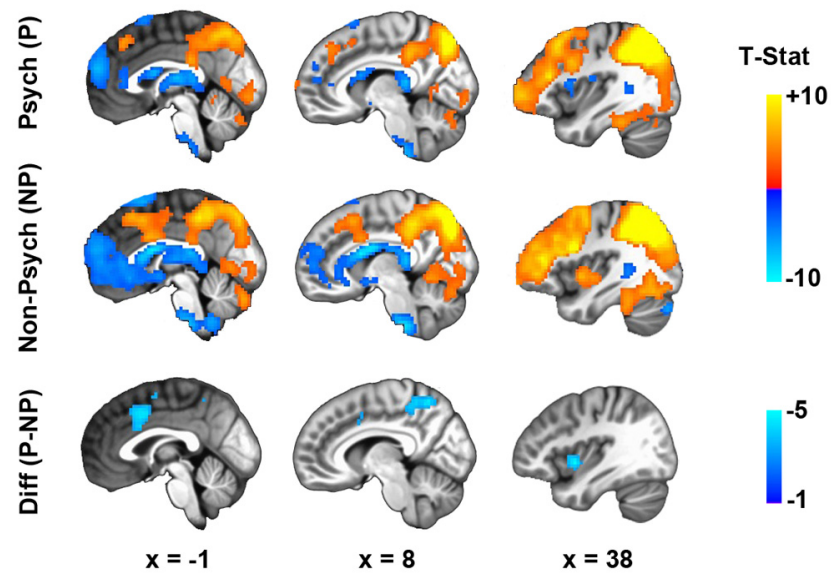

Figure 2. Group differences in functional connectivity between the R IPS, the $L d A C C$, the right precuneus, and the right insula. Top row, R IPS connectivity for the psychopathic group (Psych(P)). Middle row, R IPS connectivity for the nonpsychopathic group (Non-psych(NP)). Bottom row, Group difference maps (Diff(P-NP)) show significantly diminished connectivity between the RIPS and the left dACC extending bilaterally $(x=-1 ; i)$, the right precuneus $(x=$ $8 ; i i)$, and the right insula $(x=38$; iii) in psychopathic offenders compared with nonpsychopathic offenders $\left(p_{\mathrm{FWE}}<0.05\right)$. Results are displayed on the group average structural MRI in MNI space. Color bars indicate uncorrected $t$ values.

Similar to total PCL-R scores, we found no significant associations between factor scores and functional connectivity for the comparison primary sensory networks.

\section{Regression analysis: PCL-R facet scores}

For the DMN (Fig. 4, Table 4), higher Facet 1 (interpersonal) scores were associated with significantly diminished functional connectivity between the R IPL seed and medial prefrontal and medial parietal regions of the DMN (right ventromedial PFC, right posterior cingulate). There were no significant associations between the other three facet scores and functional connectivity for the DMN.

For the FPN (Fig. 4, Table 4), individual facet scores were associated with distinct patterns of connectivity. Higher Facet 1 (interpersonal) scores were associated with significantly decreased connectivity between the R IPS seed and bilateral precuneus of the FPN, and the right medial frontal cortex/dorsal anterior cingulate of the CON. Similarly, higher Facet 3 (lifestyle) scores were associated with significantly decreased functional connectivity between the R IPS seed and right superior frontal gyrus within the CON. In contrast, higher Facet 4 (antisocial) scores were associated with significantly increased functional connectivity between the R IPS seed and prefrontal regions of the FPN (R IPS seed: left middle frontal gyrus, right anterior medial frontal gyrus) but significantly decreased functional connectivity with right mid-insula of the CON.

For the CON (Fig. 4, Table 4), higher Facet 1 (interpersonal) scores were associated with significantly decreased functional connectivity between the $\mathrm{dACC} / \mathrm{msFC}$ seed and R IPL extending into the superior parietal lobule of the FPN. Similarly, higher Facet 2 (affective) scores predicted significantly decreased functional connectivity between the R aIfO seed and right postcentral gyrus/supramarginal gyrus within the CON. There were no significant associations between the other two Facet scores and functional connectivity for the CON.

Consistent with the other psychopathy scores, we found no significant associations between facet scores and comparison pri-

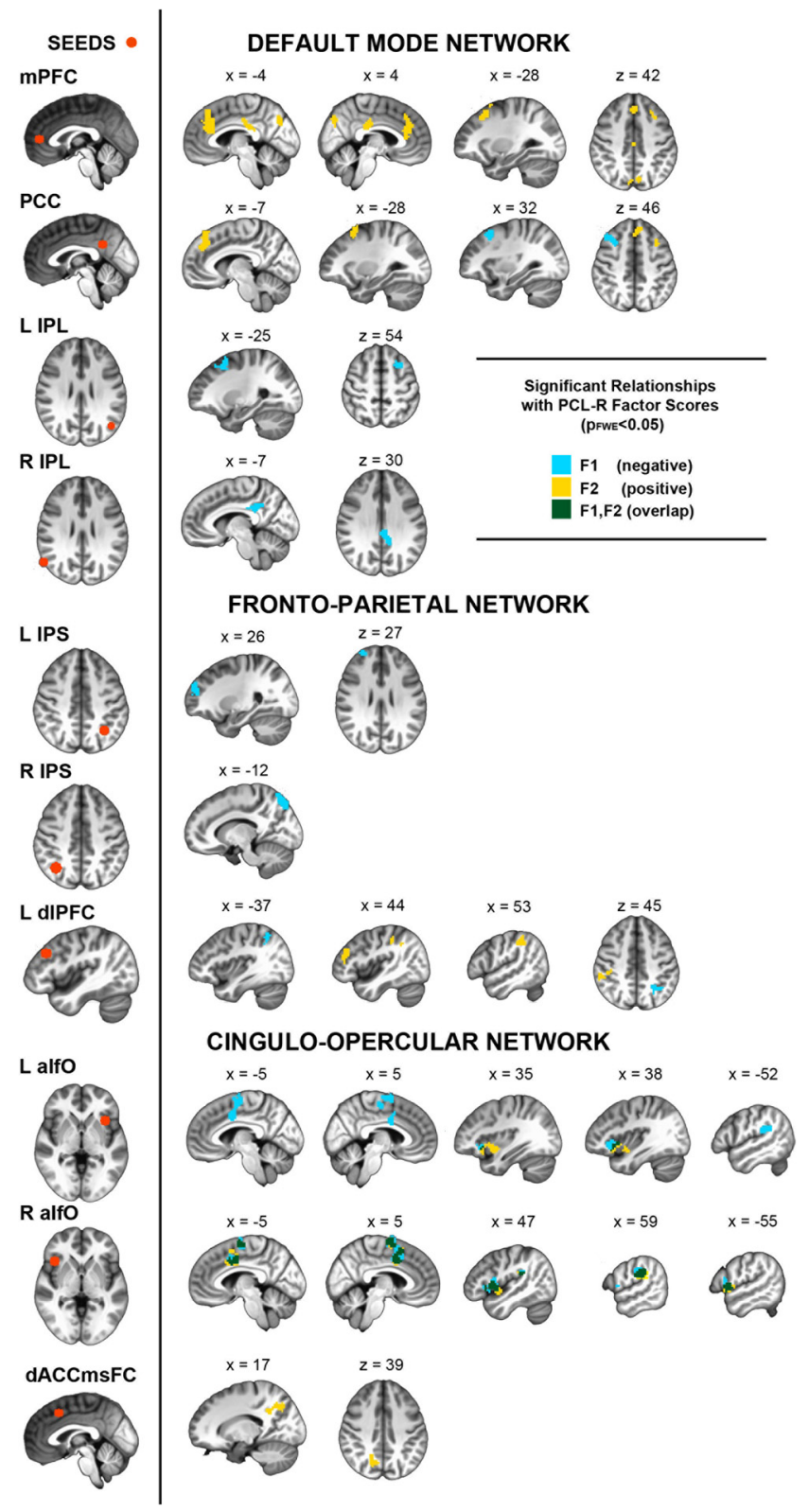

Figure 3. Distinct patterns of functional connectivity for PCL-R factor scores. Left column, Seed ROIs (red-orange) with significant regression results are displayed for each network. All results and seed ROls are displayed on the group average structural MRI in MNI space. Right column, Conjunction maps are presented to display the overlap of significant regression results $\left(p_{\mathrm{FWE}}<0.05\right)$ for both PCL-R factor scores for the DMN (rows 1-4), FPN (rows 5-7), and CON (rows 8-10) seeds. Color codes for PCL-R factor scores: light blue, Factor 1 (F1, negative relationship); yellow, Factor 2 ( $F 2$, positive relationship); green, overlap between $\mathrm{F} 1$ and $\mathrm{F} 2$ results.

mary sensory network connectivity. Whole-brain results for clusters outside the networks of interest are reported in Table 5.

\section{Discussion}

In this study, we used resting-state fMRI in a large sample of prison inmates to examine whether psychopathy is linked to alterations in functional connectivity within and between the major cortical networks of the brain. Our results demonstrate multiple significant associations between psychopathic traits and cortical connectivity. Overall psychopathy severity (total PCL-R score) was associated principally with diminished connectivity between frontal and parietal regions, whereas the major subsets 

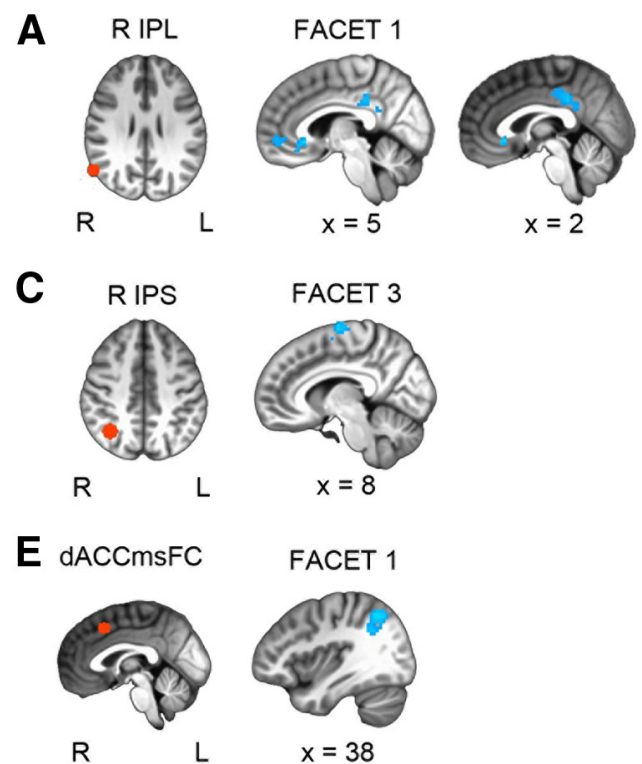
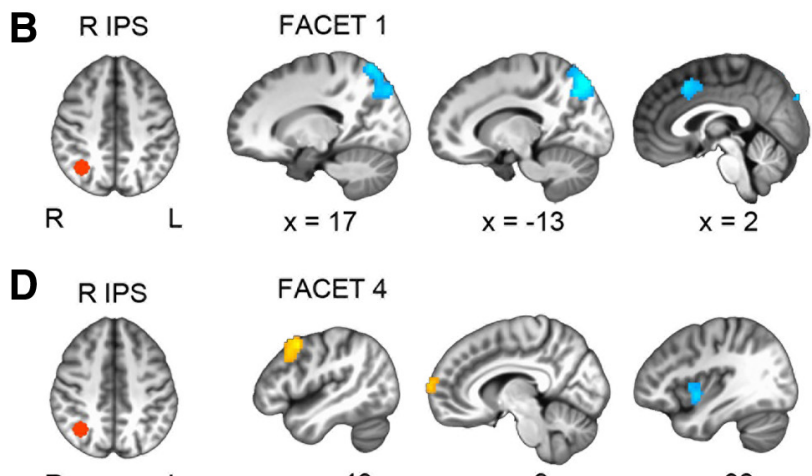

FACET 4
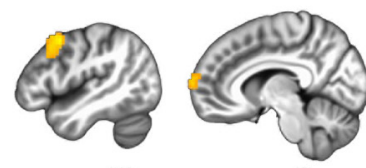

$x=8$

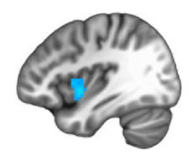

$x=38$

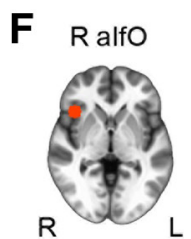

FACET 2
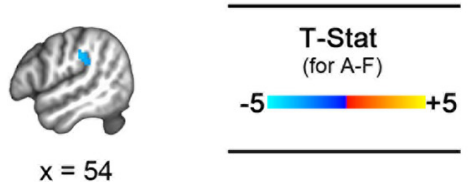

Figure 4. Distinct patterns of functional connectivity for PCL-R facet scores. $A$, Left, R IPL seed. Right, Higher Facet 1 (interpersonal) scores were associated with reduced connectivity between the R IPL and regions of the DMN. B, Left, R IPS seed. Right, Higher Facet 1 (interpersonal) scores were associated with reduced connectivity between the R IPS, pC, and dACC. C, Left, R IPS seed. Right, Higher Facet 3 (lifestyle) scores were associated with reduced connectivity between the R IPS and the superior frontal gyrus. D, Left, R IPS seed. Right, Higher Facet 4 (antisocial) scores were associated with greater connectivity between R IPS and regions of the FPN but reduced connectivity with insula. E, Left, dACC/msFC seed. Right, Higher Facet 1 (interpersonal) scores were associated with reduced functional connectivity between the dACC/msFC and IPL. $\boldsymbol{F}$, Left, $R$ alf0 seed. Right, Higher Facet 2 (affective) scores were associated with diminished connectivity between the $R$ alf0 and supramarginal gyrus. Significant regression results $\left(p_{\mathrm{FWE}}<0.05\right)$ are displayed on the group average structural MRI in MNI space. Color bar indicates uncorrected $t$ values for $\boldsymbol{A}-\boldsymbol{F}$.

\section{Table 4. Resting-state functional connectivity results: facet scores}

\begin{tabular}{|c|c|c|c|}
\hline Seed & Brain region & MNI coordinates & Cluster size (voxels), $t$ value \\
\hline \multicolumn{4}{|c|}{ Regression results: main cortical networks of interest } \\
\hline \multicolumn{4}{|l|}{ DMN } \\
\hline \multicolumn{4}{|c|}{ Facet 1 /interpersonal } \\
\hline RIPL & Right posterior cingulate & $2,-36,36$ & $173,-3.70$ \\
\hline RIPL & Right subgenual anterior cingulate extending to $\mathrm{mPFC}$ & $5,24,-6$ & $117,-4.21$ \\
\hline \multicolumn{4}{|c|}{ 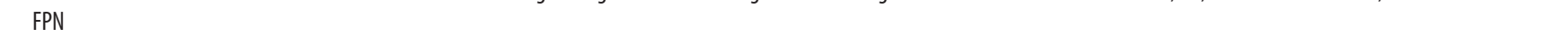 } \\
\hline \multicolumn{4}{|c|}{ Facet 1/interpersonal } \\
\hline RIPS & Right precuneus & $17,-66,63$ & $321,-4.59$ \\
\hline RIPS & Left precuneus & $-13,-78,51$ & $285,-5.64$ \\
\hline RIPS & Right medial frontal gyrus extending to dorsal anterior cingulate & $2,18,42$ & $101,-4.18$ \\
\hline \multicolumn{4}{|c|}{ 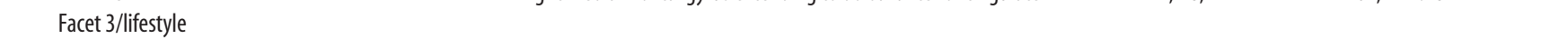 } \\
\hline RIPS & Right superior frontal gyrus extending to medial frontal gyrus & $8,-9,72$ & $192,-4.01$ \\
\hline \multicolumn{4}{|c|}{ Facet 4/antisocial } \\
\hline RIPS & Left middle frontal gyrus & $-46,9,48$ & $126,5.02$ \\
\hline RIPS & Right anterior medial frontal gyrus (BA10) & $8,69,9$ & $89,3.85$ \\
\hline RIPS & Right mid-insula & $38,3,-3$ & $84,-4.10$ \\
\hline \multicolumn{4}{|l|}{$\mathrm{CON}$} \\
\hline \multicolumn{4}{|c|}{ Facet 1/interpersonal } \\
\hline $\mathrm{dACCmsFC}$ & Right IPL extending to superior parietal lobule & $38,-57,45$ & $125,-4.12$ \\
\hline \multicolumn{4}{|l|}{ Facet 2/affective } \\
\hline Ralf0 & Right postcentral gyrus extending to supramarginal gyrus & $-21,45,79$ & $79,-4.13$ \\
\hline
\end{tabular}

Significant within-network clusters for psychopathy Facet scores from the regression analyses. All regression results reported were significant after controlling for age, substance use disorder, race, and IQ (cluster-corrected $p_{\text {FWE }}=0.05$ Holm-Bonferroni corrected, each $p<0.05$ ).

of psychopathic traits, including the two factors and four facets, exhibited distinct patterns of correlations. Factor 1 was linked exclusively to decreased cortical connectivity, whereas Factor 2 was linked exclusively to increased cortical connectivity. Similarly, Facets 1 and 2 were linked exclusively to decreased cortical connectivity, whereas Facet 4 was associated primarily with increased cortical connectivity. We did not find evidence for associations between connectivity and psychopathy scores for the comparison sensory networks. Here we consider each of the major findings in turn.
With respect to overall psychopathy severity, both the regression analysis and the between-group analysis revealed reduced functional connectivity between the right superior parietal cortex and the dACC, which are regions of the FPN and CON, respectively. The regression analysis included data from 142 inmates with a wide range of psychopathy severity (total PCL-R scores range, 5-36), whereas the between-groups analysis included 46 psychopathic and 49 nonpsychopathic offenders, respectively. This is the largest sample size ever reported in a study of restingstate functional connectivity of psychopathy. The convergent re- 
Table 5. Whole-brain results for rest-state functional connectivity outside networks of interest

\begin{tabular}{|c|c|c|c|}
\hline Seed & Brain region, $\mathrm{PCL}-\mathrm{R}$ score & MNI coordinates & Cluster size (voxels), $t$ value \\
\hline \multicolumn{4}{|c|}{ Regression results: main cortical networks of interest } \\
\hline \multicolumn{4}{|c|}{ DMN } \\
\hline \multicolumn{4}{|l|}{ Facet 4/antisocial } \\
\hline $\mathrm{PCC}$ & Bilateral primary visual cortex & $-1,-81,12$ & $195,4.17$ \\
\hline \multicolumn{4}{|l|}{ FPN } \\
\hline \multicolumn{4}{|l|}{ Total PCL-R } \\
\hline RIPS & Left inferior temporal/fusiform gyrus & $-43,-45,-15$ & $87,-4.52$ \\
\hline $\mathrm{R}$ dIPFC & Left lingual gyrus & $-22,-54,-3$ & $97,-5.11$ \\
\hline \multicolumn{4}{|l|}{ Factor 1} \\
\hline LIPS & Right cerebellum & $20,-81,42$ & $81,-4.46$ \\
\hline RIPS & Left inferior temporal-occipital/fusiform gyrus & $-40,-69,-21$ & $98,-4.07$ \\
\hline L dIPFC & Right middle occipital gyrus & $26,-87,15$ & $95,-4.08$ \\
\hline R dIPFC & Left primary visual cortex & $-4,-87,-9$ & $103,-4.84$ \\
\hline R dIPFC & Left ventral occipital cortex & $-19,-78,-12$ & $94,-4.26$ \\
\hline \multicolumn{4}{|l|}{ Factor 2} \\
\hline $\mathrm{R}$ dIPFC & Left ventral occipital cortex & $-25,-72,-21$ & $176,4.28$ \\
\hline R dIPFC & Left cerebellum & $-25,-54,-33$ & $128,4.41$ \\
\hline \multicolumn{4}{|l|}{ Facet 1 /interpersonal } \\
\hline RIPS & Left fusiform gyrus/inferior temporal cortex & $-43,-54,-24$ & $176,-4.49$ \\
\hline RIPS & Right inferior frontal gyrus & $50,9,24$ & $139,-4.37$ \\
\hline \multicolumn{4}{|l|}{$\mathrm{CON}$} \\
\hline \multicolumn{4}{|l|}{ Total PCL-R } \\
\hline Lalf0 & Right cuneus extending to lingual gyrus & $2,-81,18$ & $135,-4.09$ \\
\hline Ralf0 & Right caudate extending to subgenual anterior cingulate & $11,18,-3$ & $89,4.66$ \\
\hline \multicolumn{4}{|c|}{ 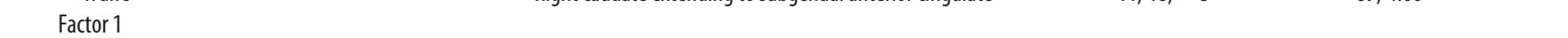 } \\
\hline Ralf0 & Right primary visual cortex, (cluster extends bilaterally) & $2,-93,3$ & $344,-4.39$ \\
\hline R alf0 & Right precentral gyrus & $44,-6,63$ & $101,-4.89$ \\
\hline \multicolumn{4}{|l|}{ Facet 1 /interpersonal } \\
\hline Ralf0 & Bilateral primary visual cortex & $-4,-96,9$ & $758,-5.89$ \\
\hline \multicolumn{4}{|l|}{ Facet 2/affective } \\
\hline R alf0 & Right lingual gyrus & $5,-93,12$ & $77,-4.02$ \\
\hline $\mathrm{dACCmsFC}$ & Right lingual gyrus & $20,-84,33$ & $104,-4.31$ \\
\hline Lalf0 & Left postcentral gyrus extending to precentral gyrus & $-49,-12,42$ & $72,-3.90$ \\
\hline \multicolumn{4}{|l|}{ Facet 4/antisocial } \\
\hline $\mathrm{dACC} / \mathrm{msFC}$ & Right cuneus & $20,-87,33$ & $73,-4.53$ \\
\hline \multicolumn{4}{|c|}{ Regression results: comparison networks } \\
\hline \multicolumn{4}{|c|}{ AN } \\
\hline \multicolumn{4}{|l|}{ Factor 1} \\
\hline Left Heschl's gyrus & Right mid-insula/posterior insula & $41,-6,12$ & $84,-4.18$ \\
\hline \multicolumn{4}{|l|}{ Facet 3/lifestyle } \\
\hline Right Heschl's gyrus & Left parahippocampal gyrus & $-25,-30,-12$ & $129,3.97$ \\
\hline
\end{tabular}

Significant clusters outside the networks of interest for psychopathy scores (total PCL-R, Factor 1, and Factor 2) from the regression analyses. All regression results reported were significant after controlling for age, SUD, race, and IO (cluster-corrected $p_{\mathrm{FWE}}=0.05$; Holm-Bonferroni corrected, each $p<0.05$ ).

sults between analyses indicate that diminished parietal-dACC connectivity is a robust neurobiological correlate of psychopathy. Although this functional connectivity result is novel, a number of previous studies have linked psychopathy with dACC dysfunction (Kiehl et al., 2001; Müller et al., 2003; Birbaumer et al., 2005; Koenigs, 2012; Ly et al., 2012; Meffert et al., 2013; ContrerasRodríguez et al., 2014; Cope et al., 2014). For example, task-based fMRI studies have associated psychopathy with decreased dACC activity across a variety of affective paradigms (Kiehl et al., 2001; Müller et al., 2003; Birbaumer et al., 2005; Meffert et al., 2013; Cope et al., 2014). Furthermore, two resting-state fMRI studies have reported diminished dACC-insula connectivity in psychopathy (Ly et al., 2012; Contreras-Rodríguez et al., 2014). Although the functional significance of decreased parietal-dACC connectivity in psychopathy is unknown, some theories suggest the interaction between these regions, as portions of the FPN and CON or as part of the unitary frontoparietal control system, could be important for integrating salient emotional and cognitive information to facilitate goal-directed action (Vincent et al., 2008; Menon, 2011). Thus, in psychopathy, disrupted communication between regions of the FPN and CON (e.g., parietal-dACC connectivity) could lead to deficits in directing attention to salient stimuli. Behaviorally, this could account for impairments in psychopathy in the allocation of attention to salient external stimuli (e.g., threat-related cues; Newman et al., 1997, 2010; Hiatt et al., 2004; Glass and Newman, 2009). However, future neuroimaging and behavioral work will be crucial for understanding the relationship between parietal-dACC connectivity and psychopathic traits.

Although previous research has identified diminished DMN connectivity in psychopathy (Glenn et al., 2009; Motzkin et al., 2011), we did not observe this relationship for overall psychopathy severity in the present study. However, we did find distinct DMN connectivity associations with individual factor and facet scores-with diminished DMN connectivity related to Factor 1 and Facet 1 but enhanced connectivity related to Factor 2. Thus, one potential explanation of our null findings for overall psychopathy is that the distribution of factor/facet scores was different from the previous studies (e.g., greater number of participants with high Factor 1/Facet 1 scores; Glenn et al., 2009; Motzkin et al., 2011). 
Additional work in an independent sample is necessary to determine the precise relationships among overall psychopathy, psychopathy factors, and DMN connectivity.

With respect to individual factor and facet scores, our study demonstrates a striking neural dissociation for the major components of psychopathic personality. Factor 1, which includes the interpersonal and affective features of psychopathy (e.g., callous, egocentric, manipulative, and emotionally shallow) was linked to diminished connectivity in each of the three main cortical networks of interest (DMN, FPN, and CON). Similarly, Facet 1, the interpersonal traits also included in Factor 1, was associated with decreased connectivity in the same main networks. In contrast, Factor 2, which includes the lifestyle and antisocial features of psychopathy (e.g., impulsive, irresponsible, parasitic, and criminally versatile) was linked to heightened connectivity in the same networks. Facet 4, the antisocial traits also included in Factor 2, was associated with primarily increased connectivity in the FPN. Despite the fact that the two factor scores and four facet scores are generally positively correlated (factor scores, $r=0.68$ in this inmate sample), these brain imaging findings suggest that the neurobiological correlates of each factor and facet are clearly separable. These results are also consistent with neuroimaging studies of psychopathy reporting distinct neural correlates for psychopathy factor and facet scores (Glenn et al., 2009; Contreras-Rodríguez et al., 2014). Specifically, Contreras-Rodríguez et al. (2014) found negative correlations between Factor 1 scores and gray matter volume but positive correlations between Factor 2 scores and gray matter volume for several brain regions, including the medial dorsal PFC, frontal operculum, and lateral PFC. During a moral decision-making fMRI task, Glenn et al. (2009) found an association between Facet 1 and decreased activity in the mPFC, PCC, and IPL of the DMN but no DMN associations with other facets. It is important to note that the dissociations observed here were not an artifact attributable to the partial correlations of factor scores (i.e., including Factor 2 score as a covariate for the Factor 1 analysis and vice versa). Even the zero-order correlations between functional connectivity values and each factor score (without covarying for the other) supports the same pattern of results obtained from the factor score regression analyses (Table 6). This partial correlation method of parsing the unique relationship between each factor score and a dependent measure of interest is standard practice in psychopathy research (Patrick et al., 1993; Patrick, 1994; Frick et al., 1999; Verona et al., 2001).

Perhaps the most remarkable dissociation for the two factors was observed in the connectivity between the anterior insula and dACC regions of the CON. The CON, also referred to as the "salience network" (Seeley et al., 2007), may play an important role in several interrelated functions germane to psychopathy, including empathy (Engen and Singer, 2013), salience detection (Seeley et al., 2007), and cognitive control (Dosenbach et al., 2007; Menon and Uddin, 2010). Recent work has also suggested that a dACC-anterior insula network may function to coordinate relative levels of activity in the DMN (which has been linked to internally directed attention, such as mind wandering and selfreflection) and FPN (which has been linked to externally directed attention, such as cognitively demanding tasks and external stimulus processing; Sridharan et al., 2008; Goulden et al., 2014). Future work could examine whether Factor 1 and Factor 2 traits exhibit similar dissociations with regard to the flexible reallocation of attention between internal thoughts (Newman and Lorenz, 2003; Koenigs et al., 2010) and salient external stimuli (e.g., threat/emotion-related cues; Newman et al., 1997, 2010; Hiatt et al., 2004; Baskin-Sommers et al., 2009; Glass and New-
Table 6. Zero-order correlations between factor scores and rest-state connectivity

\begin{tabular}{|c|c|c|c|}
\hline$\overline{\text { Seed }}$ & Brain region & MNI coordinates & $t$ value, $R^{2}$ \\
\hline \multicolumn{4}{|c|}{ Regression results: main } \\
\hline \multicolumn{4}{|c|}{ cortical networks } \\
\hline \multicolumn{4}{|c|}{ of interest } \\
\hline \multicolumn{4}{|l|}{ DMN } \\
\hline \multicolumn{4}{|l|}{ Factor 1} \\
\hline $\mathrm{PCC}$ & $\begin{array}{l}\text { Right superior frontal } \\
\text { gyrus }\end{array}$ & $32,18,51$ & $-3.61,0.10^{* * *}$ \\
\hline LIPL & Left superior frontal gyrus & $-25,12,54$ & $-2.38,0.04^{*}$ \\
\hline RIPL & Left posterior cingulate & $-7,-36,30$ & $-3.26,0.08^{* *}$ \\
\hline \multicolumn{4}{|l|}{ Factor 2} \\
\hline $\mathrm{mPFC}$ & Left dorsomedial prefrontal & $-4,30,24$ & $3.19,0.08^{* *}$ \\
\hline $\mathrm{mPFC}$ & Left superior frontal gyrus & $-16,12,63$ & $3.17,0.08^{* *}$ \\
\hline $\mathrm{mPFC}$ & Right posterior cingulate & $5,-27,30$ & $3.25,0.08^{* *}$ \\
\hline $\mathrm{mPFC}$ & Left precuneus & $-1,-75,33$ & $2.19,0.04^{*}$ \\
\hline PCC & $\begin{array}{l}\text { Left dorsomedial prefron- } \\
\text { tal cortex }\end{array}$ & $-7,36,51$ & $3.20,0.08^{* *}$ \\
\hline $\mathrm{PCC}$ & $\begin{array}{l}\text { Left superior frontal gyrus } \\
\text { extending to middle } \\
\text { frontal gyrus }\end{array}$ & $-28,12,60$ & $2.50,0.05^{*}$ \\
\hline
\end{tabular}

FPN

Factor 1

LIPS

RIPS

L dIPFC

Right superior frontal
gyrus
Left precuneus
Left superior parietal
lobule

$26,54,27-3.88,0.12^{* * *}$

$-13,-78,51-4.03,0.12^{* * *}$

Factor 2

L dIPFC

LdIPFC

Right middle frontal gyrus

Right supramarginal gyrus

CON

Factor 1

Lalf0
Right dorsal anterior cingulate/mesial fron-
tal cortex

Lalfo

Lalfo

Right anterior insula

Left supramarginal gyrus

Right dorsal anterior cingulate (cluster extends bilaterally)

Ralf0

Right inferior frontal gyrus extending to insula

Ralf0

Left inferior frontal gyrus

extending to insula

$\begin{array}{ll}44,36,24 & 3.11,0.07^{* *} \\ 53,-39,45 & 2.99,0.07^{* *}\end{array}$

Factor 2

Lalf0

R alf0

Right mid-insula extending to anterior insula

Left dorsal anterior cingulate (cluster extends bilaterally)

Ralf0

Right postcentral gyrus extending to supramarginal gyrus

Ralf0

Right inferior frontal gyrus extending to insula

Ralf0

Ralf0

$\mathrm{dACC} / \mathrm{msFC}$ Right medial frontal gyrus Left inferior frontal gyrus Right precuneus extending

$5,0,66$ $-3.26,0.08^{* *}$ $38,21,-6 \quad-2.11,0.04^{*}$ $-52,-33,21 \quad-2.34,0.04^{*}$ $5,-3,69-3.04,0.07^{* *}$ $56,6,15-2.11,0.04^{*}$ $-55,9,3$ $-2.13,0.04^{*}$ to posterior cingulate

Within-network clusters for psychopathy factor scores from the zero-order correlation analyses. All zero-orde correlation results reported only included Factor 1 or Factor 2 scores, respectively. ${ }^{*} p<0.05,{ }^{* *} p<0.01,{ }^{* * *} p<$ $0.001{ }^{* * * *} p<0.0001 ;{ }^{\#} p>0.1$. 
man, 2009). In addition, task-based fMRI studies using emotionrelated, cognitive, or social cognition tasks could be used to examine whether insula-dACC dysfunction is linked to altered DMN-FPN dynamics in psychopathy. More broadly, future studies could explore the relationship between cortical network connectivity (i.e., resting state) and relevant cognitive and emotional measures (e.g., executive function, self-related, and empathy) in relation to factors and facets of psychopathy.

We note that the observed relationships between factors scores and insula-dACC connectivity bear striking resemblance to the relationships between factor scores and anxiety. Like insula-dACC connectivity, anxiety is related negatively to Factor 1 scores but related positively to Factor 2 scores (Derefinko, 2014). Interestingly, CON connectivity/activity (in particular the anterior insula) is correlated positively with anxiety in healthy subjects (Seeley et al., 2007) and has been implicated in anxiety disorders (Menon, 2011). Although debate remains regarding the precise relationship between anxiety and psychopathy (in terms of both factor scores and psychopathy subtypes; Skeem et al., 2011), this combination of findings suggests that the delineation of the psychobiological mechanisms of psychopathic traits could benefit from future research on the link between insula-dACC connectivity, anxiety, and factor scores, as well as psychopathy subtypes. If these dissociable functional connectivity findings reflect distinct etiopathological mechanisms for Factor 1 and Factor 2 traits, then the development of more effective treatment and prevention strategies for psychopathy may benefit from targeting these traits separately. Furthermore, it is possible that neuroimaging measures could offer more accurate prognostic information than the standard interview assessment of psychopathic traits and behaviors (Aharoni et al., 2013).

In summary, here we have reported novel findings of functional brain abnormalities in psychopathic criminals (using both continuous and between-group comparison approaches). More specifically, we have demonstrated evidence of altered interactions within multiple cortical networks, including distinct network connectivity characteristics for individual psychopathy factors and facets. These results bolster an emerging literature on the neuropsychological basis of psychopathy.

\section{References}

Aharoni E, Vincent GM, Harenski CL, Calhoun VD, Sinnott-Armstrong W, Gazzaniga MS, Kiehl KA (2013) Neuroprediction of future rearrest. Proc Natl Acad Sci U S A 110:6223-6228. CrossRef Medline

Anderson NE, Kiehl KA (2012) The psychopath magnetized: insights from brain imaging. Trends Cogn Sci 16:52-60. CrossRef Medline

Andrews-Hanna JR, Snyder AZ, Vincent JL, Lustig C, Head D, Raichle ME, Buckner RL (2007) Disruption of large-scale brain systems in advanced aging. Neuron 56:924-935. CrossRef Medline

Avants B, Gee JC (2004) Geodesic estimation for large deformation anatomical shape averaging and interpolation. Neuroimage 23 [Suppl 1]:S139-S150.

Baskin-Sommers AR, Zeier JD, Newman JP (2009) Self-reported attentional control differentiates the major factors of psychopathy. Pers Individ Dif 47:626-630. CrossRef Medline

Birbaumer N, Veit R, Lotze M, Erb M, Hermann C, Grodd W, Flor H (2005) Deficient fear conditioning in psychopathy: a functional magnetic resonance imaging study. Arch Gen Psychiatry 62:799-805. CrossRef Medline

Blair RJ (2010) Neuroimaging of psychopathy and antisocial behavior: a targeted review. Curr Psychiatry Rep 12:76-82. CrossRef Medline

Boveroux P, Vanhaudenhuyse A, Bruno MA, Noirhomme Q, Lauwick S, Luxen A, Degueldre C, Plenevaux A, Schnakers C, Phillips C, Brichant JF, Bonhomme V, Maquet P, Greicius MD, Laureys S, Boly M (2010) Breakdown of within- and between-network resting state functional magnetic resonance imaging connectivity during propofol-induced loss of consciousness. Anesthesiology 113:1038-1053. CrossRef Medline

Carp J (2012) The secret lives of experiments: methods reporting in the fMRI literature. Neuroimage 63:289-300. CrossRef Medline
Cleckley H (1976) The mask of sanity, Ed 5. St. Louis: Mosby.

Contreras-Rodríguez O, Pujol J, Batalla I, Harrison BJ, Soriano-Mas C, Deus $\mathrm{J}$, López-Solà M, Macià D, Pera V, Hernández-Ribas R, Pifarré J, Menchón JM, Cardoner N (2014) Functional connectivity bias in the prefrontal cortex of psychopaths. Biol Psychiatry. Advance online publication. Retrieved March 11, 2015. doi:10.1016/j.biopsych.2014.03.007. CrossRef Medline

Cope LM, Vincent GM, Jobelius JL, Nyalakanti PK, Calhoun VD, Kiehl KA (2014) Psychopathic traits modulate brain responses to drug cues in incarcerated offenders. Front Hum Neurosci 8:87. CrossRef Medline

Cox RW (1996) AFNI: software for analysis and visualization of functional magnetic resonance neuroimages. Comput Biomed Res 29:162-173. CrossRef Medline

de Oliveira-Souza R, Hare RD, Bramati IE, Garrido GJ, Azevedo Ignácio F, Tovar-Moll F, Moll J (2008) Psychopathy as a disorder of the moral brain: Fronto-temporo-limbic grey matter reductions demonstrated by voxelbased morphometry. Neuroimage 40:1202-1213. CrossRef Medline

Derefinko KJ (2014) Psychopathy and low anxiety: meta-analytic evidence for the absence of inhibition, not affect. J Pers. Advance online publication. Retrieved March 11, 2015. doi:10.1111/jopy.12124. CrossRef Medline

Dosenbach NUF, Fair DA, Miezin FM, Cohen AL, Wenger KK, Dosenbach RAT, Fox MD, Snyder AZ, Vincent JL, Raichle ME, Schlaggar BL, Petersen SE (2007) Distinct brain networks for adaptive and stable task control in humans. Proc Natl Acad Sci U S A 104:11073-11078. CrossRef Medline

Engen HG, Singer T (2013) Empathy circuits. Curr Opin Neurobiol 23:275282. CrossRef Medline

Ermer E, Cope LM, Nyalakanti PK, Calhoun VD, Kiehl KA (2012) Aberrant paralimbic gray matter in criminal psychopathy. J Abnorm Psychol 121: 649-658. CrossRef Medline

First M (2002) Structured clinical interview for DSM-IV-TR axis I disorders, research version, non-patient edition (SCID-I/NP). New York: Biometrics Research, New York State Psychiatric Institute.

Forman SD, Cohen JD, Fitzgerald M, Eddy WF, Mintun MA, Noll DC (1995) Improved assessment of significant activation in functional magnetic resonance imaging (fMRI): use of a cluster-size threshold. Magn Res Med 33:636-647. CrossRef Medline

Fox MD, Snyder AZ, Vincent JL, Corbetta M, Van Essen DC, Raichle ME (2005) The human brain is intrinsically organized into dynamic, anticorrelated functional networks. Proc Natl Acad Sci U S A 102:9673-9678. CrossRef Medline

Frick JP, Lilienfeld SO, Ellis M, Loney B, Silverthorn P (1999) The association between anxiety and psychopathy dimensions in children. J Abnorm Child Psychol 27:383-392. CrossRef Medline

Glass SJ, Newman JP (2009) Emotion processing in the criminal psychopath: the role of attention in emotion-facilitated memory. J Abnorm Psychol 118:229-234. CrossRef Medline

Glenn AL, Raine A, Schug RA (2009) The neural correlates of moral decision-making in psychopathy. Mol Psychiatry 14:5-6. CrossRef Medline

Goulden N, Khusnulina A, Davis NJ, Bracewell RM, Bokde AL, McNulty JP, Mullins PG (2014) The salience network is responsible for switching between the default mode network and the central executive network: replication from DCM. Neuroimage 99:180-190. CrossRef Medline

Hare R (2003) Manual for the revised psychopathy checklist. Toronto: Multi-Health Systems.

Hare RD, Neumann CS (2005) Structural models of psychopathy. Curr Psychiatry Rep 7:57-64. CrossRef Medline

Hare RD, Harpur TJ, Hakstian AR, Forth AE, Hart SD, Newman JP (1990) The revised psychopathy checklist: reliability and factor structure. Psychol Assess 2:338-341. CrossRef

Harris G, Rice M, Cormier C (1991) Psychopathy and violent recidivism. Law Hum Behav 15:625-637. CrossRef

Hiatt KD, Schmitt WA, Newman JP (2004) Stroop tasks reveal abnormal selective attention among psychopathic offenders. Neuropsychology 18 : 50-59. CrossRef Medline

Holm S (1979) A simple sequentially rejective multiple test procedure. Scand J Statist 6:65-70.

Kiehl KA, Smith AM, Hare RD, Mendrek A, Forster BB, Brink J, Liddle PF (2001) Limbic abnormalities in affective processing by criminal psycho- 
paths as revealed by functional magnetic resonance imaging. Biol Psychiatry 50:677-684. CrossRef Medline

Koenigs M (2012) The role of prefrontal cortex in psychopathy. Rev Neurosci 23:253-262. CrossRef Medline

Koenigs M, Kruepke M, Newman JP (2010) Economic decision-making in psychopathy: a comparison with ventromedial prefrontal lesion patients. Neuropsychologia 48:2198-2204. CrossRef Medline

Koenigs M, Baskin-Sommers A, Zeier J, Newman JP (2011) Investigating the neural correlates of psychopathy: a critical review. Mol Psychiatry 16:792-799. CrossRef Medline

Ly M, Motzkin JC, Philippi CL, Kirk GR, Newman JP, Kiehl KA, Koenigs M (2012) Cortical thinning in psychopathy. Am J Psychiatry 169:743-749. CrossRef Medline

Maldjian JA, Laurienti PJ, Kraft RA, Burdette JH (2003) An automated method for neuroanatomic and cytoarchitectonic atlas-based interrogation of fMRI data sets. Neuroimage 19:1233-1239. CrossRef Medline

Meffert H, Gazzola V, den Boer JA, Bartels AAJ, Keysers C (2013) Reduced spontaneous but relatively normal deliberate vicarious representations in psychopathy. Brain 136:2550-2562. CrossRef Medline

Menon V (2011) Large-scale brain networks and psychopathology: a unifying triple network model. Trends Cogn Sci 15:483-506. CrossRef Medline

Menon V, Uddin LQ (2010) Saliency, switching, attention and control: a network model of insula function. Brain Struct Funct 214:655-667. CrossRef Medline

Morris SE, Cuthbert BN (2012) Research domain criteria: cognitive systems, neural circuits, and dimensions of behavior. Dialogues Clin Neurosci 14:29-37. Medline

Motzkin JC, Newman JP, Kiehl KA, Koenigs M (2011) Reduced prefrontal connectivity in psychopathy. J Neurosci 31:17348-17357. CrossRef Medline

Müller JL, Sommer M, Wagner V, Lange K, Taschler H, Röder CH, Schuierer G, Klein HE, Hajak G (2003) Abnormalities in emotion processing within cortical and subcortical regions in criminal psychopaths: evidence from a functional magnetic resonance imaging study using pictures with emotional content. Biol Psychiatry 54:152-162. CrossRef Medline

Newman JP, Lorenz AR (2003) Response modulation and emotion processing: implications for psychopathy and other dysregulatory psychopathology. In: Handbook of affective sciences (Davidson RJ, Scherer KR, Goldsmith HH, Tyler L, eds), pp 904-929. Oxford, UK: Oxford UP.

Newman JP, Schmitt WA, Voss WD (1997) The impact of motivationally neutral cues on psychopathic individuals: assessing the generality of the response modulation hypothesis. J Abnorm Psychol 106:563-575. CrossRef Medline

Newman JP, Curtin JJ, Bertsch JD, Baskin-Sommers AR (2010) Attention moderates the fearlessness of psychopathic offenders. Biol Psychiatry 67: 66-70. CrossRef Medline

Patrick CJ (1994) Emotion and psychopathy: startling new insights. Psychophysiology 31:319-330. CrossRef Medline

Patrick CJ, Bradley MM, Lang PJ (1993) Emotion in the criminal psychopath: startle reflex modulation. J Abnorm Psychol 102:82-92. CrossRef Medline

Power JD, Barnes KA, Snyder AZ, Schlaggar BL, Petersen SE (2012) Spuri- ous but systematic correlations in functional connectivity MRI networks arise from subject motion. Neuroimage 59:2142-2154. CrossRef Medline

Satterthwaite TD, Elliott MA, Gerraty RT, Ruparel K, Loughead J, Calkins ME, Eickhoff SB, Hakonarson H, Gur RC, Gur RE, Wolf DH (2013) An improved framework for confound regression and filtering for control of motion artifact in the preprocessing of resting-state functional connectivity data. Neuroimage 64:240-256. CrossRef Medline

Seeley WW, Menon V, Schatzberg AF, Keller J, Glover GH, Kenna H, Reiss AL, Greicius MD (2007) Dissociable intrinsic connectivity networks for salience processing and executive control. J Neurosci 27:2349-2356. CrossRef Medline

Skeem JL, Polaschek DL, Patrick CJ, Lilienfeld SO (2011) Psychopathic personality bridging the gap between scientific evidence and public policy. Psychol Sci Public Interest 12:95-162. CrossRef

Sridharan D, Levitin DJ, Menon V (2008) A critical role for the right frontoinsular cortex in switching between central-executive and default-mode networks. Proc Natl Acad Sci U S A 105:12569-12574. CrossRef Medline

Sylvester CM, Corbetta M, Raichle ME, Rodebaugh TL, Schlaggar BL, Sheline YI, Zorumski CF, Lenze EJ (2012) Functional network dysfunction in anxiety and anxiety disorders. Trends Neurosci 35:527-535. CrossRef Medline

Verona E, Patrick CJ, Joiner TE (2001) Psychopathy, antisocial personality, and suicide risk. J Abnorm Psychol 110:462-470. CrossRef Medline

Vincent JL, Kahn I, Snyder AZ, Raichle ME, Buckner RL (2008) Evidence for a frontoparietal control system revealed by intrinsic functional connectivity. J Neurophysiol 100:3328-3342. CrossRef Medline

Whitfield-Gabrieli S, Ford JM (2012) Default mode network activity and connectivity in psychopathology. Annu Rev Clin Psychol 8:49-76. CrossRef Medline

Yan CG, Cheung B, Kelly C, Colcombe S, Craddock RC, Di Martino A, Li Q, Zuo XN, Castellanos FX, Milham MP (2013) A comprehensive assessment of regional variation in the impact of head micromovements on functional connectomics. Neuroimage 76:183-201. CrossRef Medline

Yang Y, Raine A (2009) Prefrontal structural and functional brain imaging findings in antisocial, violent, and psychopathic individuals: a metaanalysis. Psychiatry Res 174:81-88. CrossRef Medline

Yang Y, Raine A, Lencz T, Bihrle S, LaCasse L, Colletti P (2005) Volume reduction in prefrontal gray matter in unsuccessful criminal psychopaths. Biol Psychiatry 57:1103-1108. CrossRef Medline

Yang Y, Raine A, Narr KL, Colletti P, Toga AW (2009) Localization of deformations within the amygdala in individuals with psychopathy. Arch Gen Psychiatry 66:986-994. CrossRef Medline

Yeo BTT, Krienen FM, Sepulcre J, Sabuncu MR, Lashkari D, Hollinshead M, Roffman JL, Smoller JW, Zöllei L, Polimeni JR, Fischl B, Liu H, Buckner RL (2011) The organization of the human cerebral cortex estimated by intrinsic functional connectivity. J Neurophysiol 106:1125-1165. CrossRef Medline

Zachary R (1986) Shipley institute of living scale: revised manual. Los Angeles: Western Psychological Services.

Zhang Y, Brady M, Smith S (2001) Segmentation of brain MR images through a hidden Markov random field model and the expectationmaximization algorithm. IEEE Trans Med Imaging 20:45-57. CrossRef Medline 